\title{
A multi-parametric prognostic model based on clinical features and serological markers predicts overall survival in non-small cell lung cancer patients with chronic hepatitis B viral infection
}

Shulin Chen ${ }^{1 \dagger}{ }^{\text {, Hanqing Huang }}{ }^{2 \dagger}$, Yijun Liu ${ }^{1 \dagger}$, Changchun Lai ${ }^{3}$, Songguo Peng ${ }^{1}$, Lei Zhou ${ }^{4}$, Hao Chen ${ }^{1 \dagger}$, Yiwei $\mathrm{Xu}^{5+}$ and $\mathrm{Xia} \mathrm{He}^{1 *+}$ (1)

\begin{abstract}
Background: To establish and validate a multi-parametric prognostic model based on clinical features and serological markers to estimate the overall survival (OS) in non-small cell lung cancer (NSCLC) patients with chronic hepatitis B viral (HBV) infection.

Methods: The prognostic model was established by using Lasso regression analysis in the training cohort. The incremental predictive value of the model compared to traditional TNM staging and clinical treatment for individualized survival was evaluated by the concordance index (C-index), time-dependent ROC (tdROC) curve, and decision curve analysis (DCA). A prognostic model risk score based nomogram for OS was built by combining TNM staging and clinical treatment. Patients were divided into high-risk and low-risk subgroups according to the model risk score. The difference in survival between subgroups was analyzed using Kaplan-Meier survival analysis, and correlations between the prognostic model, TNM staging, and clinical treatment were analysed.

Results: The C-index of the model for OS is 0.769 in the training cohorts and 0.676 in the validation cohorts, respectively, which is higher than that of TNM staging and clinical treatment. The tdROC curve and DCA show the model have good predictive accuracy and discriminatory power compare to the TNM staging and clinical treatment. The prognostic model risk score based nomogram show some net clinical benefit. According to the model risk score, patients are divided into low-risk and high-risk subgroups. The difference in OS rates is significant in the subgroups. Furthermore, the model show a positive correlation with TNM staging and clinical treatment.
\end{abstract}

\footnotetext{
*Correspondence: hexia@sysucc.org.cn

${ }^{\dagger}$ Shulin Chen, Hanqing Huang and Yijun Liu contributed equally to this

work

${ }^{\dagger}$ Hao Chen, Yiwei Xu and Xia He contributed equally to this work

1 State Key Laboratory of Oncology in South China, Collaborative

Innovation Center for Cancer Medicine, Guangdong Key Laboratory

of Nasopharyngeal Carcinoma Diagnosis and Therapy, Sun Yat-Sen

University Cancer Center, 651 Dongfeng Road East, Guangzhou 510060,

People's Republic of China

Full list of author information is available at the end of the article
}

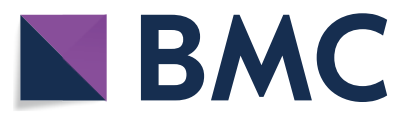

(c) The Author(s) 2020. This article is licensed under a Creative Commons Attribution 4.0 International License, which permits use, sharing, adaptation, distribution and reproduction in any medium or format, as long as you give appropriate credit to the original author(s) and the source, provide a link to the Creative Commons licence, and indicate if changes were made. The images or other third party material in this article are included in the article's Creative Commons licence, unless indicated otherwise in a credit line to the material. If material is not included in the article's Creative Commons licence and your intended use is not permitted by statutory regulation or exceeds the permitted use, you will need to obtain permission directly from the copyright holder. To view a copy of this licence, visit http://creativecommons.org/licenses/by/4.0/. The Creative Commons Public Domain Dedication waiver (http://creativecommons.org/publicdomain/zero/1.0/) applies to the data made available in this article, unless otherwise stated in a credit line to the data. 
Conclusions: The prognostic model showed good performance compared to traditional TNM staging and clinical treatment for estimating the OS in NSCLC ( $\mathrm{HBV}+)$ patients.

Keywords: Hepatitis B virus, Lasso regression, Model, Non-small cell lung cancer, Prognostic

\section{Background}

At present, lung cancer is the leading cause of cancer morbidity and mortality worldwide [1]. Non-smallcell lung cancer (NSCLC) accounts for $75-80 \%$ of all lung malignancies [2]. The 5-year survival of NSCLC patients is generally poor because of late diagnosis, frequent relapse, and the lack of effective systemic therapy [3].

Hepatitis B virus (HBV) is one of the most prevalent and most serious types of viral hepatitis, and the prevalence of HBV in China is high [4]. Therefore, it is reasonable to hypothesize that a HBV infection may be an important comorbidity factor in NSCLC patients in China. Previous studies have shown that HBV associated with several extra-hepatic cancers [5-7], In addition, diffuse large B-cell lymphoma [8] and multiple myeloma [9] patients with HBV infection have poor survival outcomes compared to non-infected patients. Together, these results implied that NSCLC patients with HBV infection should be distinguished from uninfected patients because they have different clinical characteristics, outcomes and prognostic factors. This may aid in the development of a distinct prognostic predictive model for NSCLC patients with HBV infection.

Currently, the TNM (tumor, lymph node, metastasis) stage is a widely used staging system for predicting the outcome of NSCLC patients [10]. However, patients within a similar TNM stage show different genetic, cellular, and clinicopathological characteristics, and exhibit a wide spectrum of clinical survival outcomes. This indicates the need for additional prognostic factors to complement the TNM staging to better predict the outcome of the NSCLC patients [11-13]. Therefore, many studies have reported some prognostic factors that might improve the predict the survival of NSCLC patients [14-16]. Together, these findings could help identify patients that would benefit from novel therapeutic strategies or, alternatively, if additional treatment methods need to be pursued.

Thus, the present retrospective study aimed to develop and validate a multi-parametric prognostic model based on clinical features and serological markers to estimate the overall survival (OS) in NSCLC $\mathrm{HBV}(+)$ patients and assess its incremental value to the traditional staging system and clinical treatment for the estimation of OS.

\section{Material and methods \\ Patient selection and data collection}

First diagnosed NSCLC (HBV+) patients who were treated at the Sun Yat-sen University Cancer Center (Guangzhou, China) between January 2008 and December 2010 were retrospectively enrolled in this study. This study was approved by the Hospital Ethics Committee in Sun Yat-sen University Cancer Center (Guangzhou, China). The inclusion criteria were as follows: (a) pathological evidence of NSCLC; (b) patients without pathological diagnosis or with previous or concomitant malignancies; (c) positive for hepatitis B surface antigen (HbsAg); (d) no co-infected other types of hepatitis viruses; (e) complete baseline clinical information, laboratory, and follow-up data.

The following relevant clinical and serological data were collected for each enrolled patient at the time of diagnosis and before any treatment: age, gender, family history, body mass index (BMI), tumor size, clinical treatment, Tumor Node Metastasis stage (TNM stage) [17], white blood cells (WBC), neutrophils (N), lymphocytes (L), platelet (PLT), hepatitis B surface antigen (HbsAg), hepatitis B surface antibody (HBsAb), hepatitis $B$ envelope antigen ( $\mathrm{HBeAg}$ ), hepatitis $B$ envelope antibody(HBeAb), hepatitis B core antibody (HBcAb), hepatitis $B$ core antigen (HBcAb), albumin (ALB), alkaline phosphatase (ALP), apolipoprotein AI (APOA), apolipoprotein $\mathrm{B}$ (APOB), C-reactive protein (CRP), lactic dehydrogenase (LDH), glutamyl transpeptidase (GGT), total bilirubin (TBIL), and direct bilirubin (DBIL). The NLR represented the ratio of neutrophils to lymphocytes ratio [18]; the PLR represented the ratio of platelets to lymphocytes [18]; the SLR was the ratio of aspartate aminotransferase (AST) to alanine transaminase (ALT) [19]; ABR was the ratio of APOA to APOB [20]; CAR was the ratio of CRP to ALB ratio [21]; prognostic index (PI): score 0 for CRP $10 \mathrm{mg} / \mathrm{L}$ or less and a WBC count of $11 \times 10^{9} / \mathrm{L}$ or less, patients with only one of these abnormalities were allocated a score of 1 , and patients with an elevation of both levels were elevated were allocated a score of 2 [22]. The prognostic nutritional index (PNI) was calculated according to the following formula: Alb $(\mathrm{g} / \mathrm{L})+5 \times$ lymphocyte 
count $\times 10^{9} / \mathrm{L}$ : score 0 for $\mathrm{PNI}>45$; score 1 in patients with $\mathrm{PNI} \leq 45$ [23]. The Glasgow prognostic score (GPS) was classified as follows: patients with serum CRP $>10 \mathrm{mg} / \mathrm{L}$ and albumin $<35 \mathrm{~g} / \mathrm{L}$ were classified as GPS 2; patients with CRP $>10 \mathrm{mg} / \mathrm{L}$ or albu$\min <35 \mathrm{~g} / \mathrm{L}$ were classified as GPS 1; patients with serum $C R P \leq 10 \mathrm{mg} / \mathrm{mL}$ and albumin $>35 \mathrm{~g} / \mathrm{L}$ were classified as GPS 0 [24].

\section{Patients follow up}

Follow-up of patients' survival data was obtained by means of retrieving medical records, email, and direct communication by phone. All patients were followed up until death or January 2016. The endpoint of this study was overall survival (OS), which was defined as the time interval from diagnosis to the date of the patient's death or censored at the date of the last follow-up.

\section{Statistical analyses}

Statistical analyses were performed using IBM SPSS Statistical software version 19.0 (IBMCorp., Chicago, IL, USA) and $\mathrm{R}$ version 3.6.0 (http://www.R-project.org). Categorical variables were classified based on clinical findings, and continuous variables were transformed into categorical variables based on the cut-off values of by the R package "survival" [25] and "survminer". Differences in distribution between patients in the training cohort and validation cohort were analyzed by Chi-square test. The Lasso regression analysis was utilized to select the most useful prognostic variables in the training cohort. According to the regulation weight $\lambda$, LASSO shrinks all regression coefficients towards zero and sets the coefficients of many irrelevant features to zero. The optimal values of the penalty parameter $\lambda$ were determined by tenfold cross validation with the 1 standard error of the minimum criteria (the 1-SE criteria), where the final value of $\lambda$ yielded a minimum cross validation error. Retained features with nonzero coefficients were used for regression model fitting [26, 27]. Next, a prognostic computing-based model was established for each patient through a linear combination of selected variables weighted by their respective coefficients. The $\mathrm{R}$ package "glmnet" was used for Lasso regression analysis. The incremental predictive value of the prognostic model to the traditional TNM staging and clinical treatment for individualized survival was evaluated by the Harrell's concordance index (C-index), time-dependent ROC (tdROC), and decision curve analysis [28]. The area under the curve (AUC) was calculated using the "survivalROC" package [29], and the $C$-index was computed and compared by using the "survcomp" package [30]. A nomogram (by the package of rms in R) was developed using the prognostic model risk score, TNM staging, and clinical treatment. Performance was assessed by the calibration curve in internal validation with bootstrapping (1000 bootstrap resamples) [31]. For subsequent comparison, patients were divided into high- and lowrisk groups basing on the optimal cut-off value of the prognostic model risk score, and Kaplan-Meier survival analyses and log-rank tests were used to assess differences in OS between patients in the predicted high- and low-risk groups. The correlation between the prognostic model and TNM staging or clinical treatment was evaluated by the Pearson's correlation coefficient [32]. Results with two-sided $p$ values of $<0.05$ were considered statistically significant.

\section{Results}

\section{Patient characteristics}

In this study, a total of 201 eligible patients are analyzed: 145 cases in the training cohort and 56 cases in the validation cohort. The median follow-up is 29.0 months (interquartile range (IQR):12.0-64.0) in the training cohort and 32.5 months (IQR: 11.0-60.75) in the validation cohort. The 1-, 3-, and 5-year OS rates in the training cohort are $75.2 \%, 46.9 \%$, and $31.7 \%$, respectively, and the 1-, 3-, and 5-year OS rates in the validation are $73.2 \%$, $42.9 \%$, and $26.8 \%$, respectively.

The optimal cut-off value for each continuous variable is as follows: age (40 years), BMI $\left(22.3 \mathrm{~kg} / \mathrm{m}^{2}\right)$, tumor size $(4.0 \mathrm{~cm}), \mathrm{WBC}\left(10.810^{9} / \mathrm{L}\right), \mathrm{N}\left(8.110^{9} / \mathrm{L}\right), \mathrm{L}(1.74$ $\left.10^{9} / \mathrm{L}\right)$, PLT $\left(163.010^{9} / \mathrm{L}\right)$, NLR (2.7), PLR (108.6), ALB (42.5 g/L), ALT (13.7 U/L), AST (32.2 U/L), SLR (1.5), ALP (69.6 U/L), APOA $(1.2 \mathrm{~g} / \mathrm{L})$, APOB $(1.0 \mathrm{~g} / \mathrm{L})$, ABR (0.8), CRP (6.2 mg/L), CAR (0.16), LDH (230.3 U/L), GGT (44.2 U/L), TBIL $(15.4 \mu \mathrm{mol} / \mathrm{L})$, DBIL $(3.0 \mu \mathrm{mol} / \mathrm{L})$, and PNI (48.1). The details regarding patients' clinical characteristics and serological markers are listed in Table 1. No clinical and serological parameters, except for ALB, PLR, HBeAg, HBeAb, and HBcAb have a significantly different distribution in the training cohort and validation cohort.

\section{Construction of the multi-parametric prognostic model based on clinical and serological markers}

To select prognostic clinical and serological markers, the Lasso regression analysis is performed based on the OS in the training cohort. Figure 1a shows the change in trajectory for each factor analyzed. Moreover, tenfold cross-validation is used for model establishment, and the confidence interval under each $\lambda$ is presented in Fig. 1b. The optimal value of $\lambda$ is 0.046 in the Lasso regression analysis. Thus, this value is selected as the final model, and including 10 predictors from the 34 markers that are 
Table 1 Demographics and clinical characteristics of patients in the training and validation cohort

\begin{tabular}{|c|c|c|c|}
\hline Characteristic & $\begin{array}{l}\text { Training cohort } \\
\mathrm{n}=(145) \\
\text { No. }(\%)\end{array}$ & $\begin{array}{l}\text { Validation cohort } \\
\mathrm{n}=(56) \\
\text { No. (\%) }\end{array}$ & $P$ value \\
\hline Gender & & & 0.811 \\
\hline Male & $109(75.2 \%)$ & $43(76.8 \%)$ & \\
\hline Female & $36(24.8 \%)$ & $13(23.2 \%)$ & \\
\hline Age (years) & & & 0.431 \\
\hline$\leq 40$ & $15(10.3 \%)$ & $8(14.3 \%)$ & \\
\hline$>40$ & $130(89.7 \%)$ & $48(85.7 \%)$ & \\
\hline Family history & & & 0.898 \\
\hline Yes & $35(24.1 \%)$ & $14(25.0 \%)$ & \\
\hline No & $110(75.9 \%)$ & $42(75.0 \%)$ & \\
\hline Smoking behavior & & & 0.819 \\
\hline Yes & $88(60.7 \%)$ & $33(58.9 \%)$ & \\
\hline No & 57 (39.3\%) & $23(41.1 \%)$ & \\
\hline BMI $\left(\mathrm{kg} / \mathrm{m}^{2}\right)$ & & & 0.630 \\
\hline$\leq 22.3$ & $80(55.2 \%)$ & $33(58.9 \%)$ & \\
\hline$>22.3$ & $65(44.8 \%)$ & $23(41.1 \%)$ & \\
\hline TNM stage $^{a}$ & & & 0.846 \\
\hline 1 & $34(23.4 \%)$ & $11(19.6 \%)$ & \\
\hline$\|$ & $14(9.7 \%)$ & $5(8.9 \%)$ & \\
\hline III & $50(34.5 \%)$ & $23(41.1 \%)$ & \\
\hline IV & 47 (32.4\%) & $17(30.4 \%)$ & \\
\hline Size $(\mathrm{cm})^{\mathrm{b}}$ & & & 0.911 \\
\hline$\leq 4.0$ & $79(54.5 \%)$ & $31(55.4 \%)$ & \\
\hline$>4.0$ & $66(45.5 \%)$ & $25(44.6 \%)$ & \\
\hline Treatment & & & 0.648 \\
\hline Sur & $31(21.4 \%)$ & $13(23.2 \%)$ & \\
\hline Sur and Rad/Che & 47 (32.4\%) & $18(32.1 \%)$ & \\
\hline Rad/Che & $54(37.2 \%)$ & $17(30.4 \%)$ & \\
\hline Other & $13(9.0 \%)$ & $8(14.3 \%)$ & \\
\hline WBC $\left(10^{9} / L\right)$ & & & 0.560 \\
\hline$\leq 10.8$ & $125(86.2 \%)$ & $50(89.3 \%)$ & \\
\hline$>10.8$ & $20(13.8 \%)$ & $6(10.7 \%)$ & \\
\hline \multicolumn{4}{|l|}{ Neutrophils $\left(10^{9} / \mathrm{L}\right)$} \\
\hline$\leq 8.1$ & $128(88.3 \%)$ & $51(91.1 \%)$ & 0.569 \\
\hline$>8.1$ & $17(11.7 \%)$ & $5(8.9 \%)$ & \\
\hline \multicolumn{4}{|l|}{ Lymphocyte $\left(10^{9} / \mathrm{L}\right)$} \\
\hline$\leq 1.74$ & $40(27.6 \%)$ & 17 (30.4\%) & 0.696 \\
\hline$>1.74$ & $105(72.4 \%)$ & $39(69.6 \%)$ & \\
\hline Platelet $\left(10^{9} / \mathrm{L}\right)$ & & & 0.245 \\
\hline$\leq 163.0$ & $22(15.2 \%)$ & 5 (8.9\%) & \\
\hline$>163.0$ & $123(84.8 \%)$ & 51 (91.1\%) & \\
\hline NLR & & & 0.521 \\
\hline$\leq 2.7$ & 90 (62.1\%) & $32(57.1 \%)$ & \\
\hline$>2.7$ & 55 (37.9\%) & $24(42.9 \%)$ & \\
\hline PLR & & & 0.043 \\
\hline$\leq 108.6$ & $64(44.1 \%)$ & $16(28.6 \%)$ & \\
\hline$>108.6$ & 81 (55.9\%) & $40(71.4 \%)$ & \\
\hline
\end{tabular}

Table 1 (continued)

\begin{tabular}{|c|c|c|c|}
\hline Characteristic & $\begin{array}{l}\text { Training cohort } \\
n=(145) \\
\text { No. (\%) }\end{array}$ & $\begin{array}{l}\text { Validation cohort } \\
n=(56) \\
\text { No. }(\%)\end{array}$ & $P$ value \\
\hline $\mathrm{HBsAb}$ & & & 0.107 \\
\hline Negative & $145(100.0 \%)$ & 55 (98.2\%) & \\
\hline Positive & $0(0.0 \%)$ & $1(1.8 \%)$ & \\
\hline $\mathrm{HBeAg}$ & & & 0.026 \\
\hline Negative & 142 (97.9\%) & $51(91.1 \%)$ & \\
\hline Positive & $3(2.1 \%)$ & 5 (8.9\%) & \\
\hline HBeAb & & & 0.016 \\
\hline Negative & $8(5.5 \%)$ & $9(16.1 \%)$ & \\
\hline Positive & 137 (94.5\%) & 47 (83.9\%) & \\
\hline $\mathrm{HBcAb}$ & & & 0.022 \\
\hline Negative & $0(0.0 \%)$ & $2(3.6 \%)$ & \\
\hline Positive & $145(100.0 \%)$ & $54(96.4 \%)$ & \\
\hline ALB (g/L) & & & 0.035 \\
\hline$\leq 42.5$ & 91 (62.8\%) & $26(46.4 \%)$ & \\
\hline$>42.5$ & $54(37.2 \%)$ & $30(53.6 \%)$ & \\
\hline $\operatorname{ALT}(U / L)$ & & & 0.260 \\
\hline$\leq 13.7$ & $26(17.9 \%)$ & $14(25.0 \%)$ & \\
\hline$>13.7$ & $119(82.1 \%)$ & $42(75.0 \%)$ & \\
\hline AST (U/L) & & & 0.370 \\
\hline$\leq 32.2$ & $124(85.5 \%)$ & 45 (80.4\%) & \\
\hline$>32.2$ & 21 (14.5\%) & $11(19.6 \%)$ & \\
\hline SLR & & & 0.987 \\
\hline$\leq 1.5$ & $127(87.6 \%)$ & $49(87.5 \%)$ & \\
\hline$>1.5$ & $18(12.4 \%)$ & $7(12.5 \%)$ & \\
\hline ALP (U/L) & & & 0.931 \\
\hline$\leq 69.6$ & $56(38.6 \%)$ & $22(39.3 \%)$ & \\
\hline$>69.6$ & 89 (61.4\%) & $34(60.7 \%)$ & \\
\hline APOA (g/L) & & & 0.425 \\
\hline$\leq 1.2$ & 79 (54.5\%) & 27 (48.2\%) & \\
\hline$>1.2$ & $66(45.5 \%)$ & $29(51.8 \%)$ & \\
\hline APOB (g/L) & & & 0.315 \\
\hline$\leq 1.0$ & $101(69.7 \%)$ & 43 (76.9\%) & \\
\hline$>1.0$ & 44 (30.3\%) & $13(23.2 \%)$ & \\
\hline$A B R$ & & & 0.057 \\
\hline$\leq 0.8$ & 14 (9.7\%) & $1(1.8 \%)$ & \\
\hline$>0.8$ & $131(90.3 \%)$ & 55 (98.2\%) & \\
\hline CRP (mg/L) & & & 0.443 \\
\hline$\leq 6.2$ & $82(56.6 \%)$ & $35(62.5 \%)$ & \\
\hline$>6.2$ & $63(43.6 \%)$ & $21(37.5 \%)$ & \\
\hline CAR & & & 0.278 \\
\hline$\leq 0.16$ & 81 (17.9\%) & $36(64.3 \%)$ & \\
\hline$>0.16$ & 64 (44.1\%) & $20(35.7 \%)$ & \\
\hline $\mathrm{LDH}(\mathrm{U} / \mathrm{L})$ & & & 0.755 \\
\hline$\leq 230.3$ & $119(82.1 \%)$ & 47 (83.9\%) & \\
\hline$>230.3$ & $26(17.9 \%)$ & $9(16.1 \%)$ & \\
\hline GGT (U/L) & & & 0.731 \\
\hline$\leq 44.2$ & $116(80.0 \%)$ & $46(82.1 \%)$ & \\
\hline
\end{tabular}


Table 1 (continued)

\begin{tabular}{|c|c|c|c|}
\hline Characteristic & $\begin{array}{l}\text { Training cohort } \\
\mathrm{n}=(145) \\
\text { No. }(\%)\end{array}$ & $\begin{array}{l}\text { Validation cohort } \\
\mathrm{n}=(56) \\
\text { No. (\%) }\end{array}$ & $P$ value \\
\hline$>44.2$ & $29(20.0 \%)$ & 10 (17.9\%) & \\
\hline TBIL (umol/L) & & & 0.652 \\
\hline$\leq 15.4$ & 115 (79.3\%) & $46(82.1 \%)$ & \\
\hline$>15.4$ & $30(20.7 \%)$ & $10(17.9 \%)$ & \\
\hline DBIL (umol/L) & & & 0.813 \\
\hline$\leq 3.0$ & 57 (39.3\%) & $21(37.5 \%)$ & \\
\hline$>3.0$ & 88 (60.7\%) & $35(62.5 \%)$ & \\
\hline PNI & & & 0.084 \\
\hline$\leq 48.1$ & $34(23.4 \%)$ & $7(12.5 \%)$ & \\
\hline$>48.1$ & $111(76.6 \%)$ & 49 (87.5\%) & \\
\hline PI & & & 0.521 \\
\hline 0 & 92 (63.4\%) & 40 (71.4\%) & \\
\hline 1 & 39 (26.9\%) & $11(19.7 \%)$ & \\
\hline 2 & $14(9.7 \%)$ & 5 (8.9\%) & \\
\hline GPS & & & 0.456 \\
\hline 0 & $93(64.1 \%)$ & $41(73.2 \%)$ & \\
\hline 1 & $46(31.7 \%)$ & $13(23.2 \%)$ & \\
\hline 2 & $6(4.1 \%)$ & $2(3.6 \%)$ & \\
\hline
\end{tabular}

$B M I$ body mass index, TNM tumor node metastasis stage, Sur surgery; Rad: radiotherapy, Che chemotherapy, WBC white blood cell, NLR neutrophil/ lymphocyte ratio, $P L R$ platelet/lymphocyte ratio, $A L B$ albumin, $A L T$ alanine transaminase, AST aspartate aminotransferase, SLR AST/ALT ratio, ALP alkaline phosphatase, APOA apolipoprotein Al, APOB apolipoprotein B, ABR APOA/APOB ratio, $C R P C$-reactive protein, $C A R C$-reactive protein/albumin ratio, $L D H$ lactic dehydrogenase, GGT glutamyl transpeptidase, TBIL total bilirubin, DBIL direct bilirubin, $P N /$ prognostic nutritional index, PI prognostic index, GPS Glasgow prognostic score

a TNM stage was classified according to the AJCC 7th TNM staging system

b The tumor maximum diameter

significant weighted prognostic factors: age, BMI, tumor size, PLT, PLR, ALT, GGT, LDH, TBIL, and APOA. The coefficients of the 10 predictors are presented in Fig. 1c. Subsequently, a multi-parametric prognostic model based on clinical and serological markers is constructed using the coefficients derived from the Lasso regression analysis. Next, a prognostic model risk score is calculated based on the personalized levels of the 10 predictors, by using the following formula: the prognostic model risk score $=0.679-(0.148 \times$ age $)-(0.193 \times \mathrm{BMI}+(0.101 \times$ tumor size $)-(0.554 \times \mathrm{PLT})+(0.197 \times \mathrm{PLR})-(0.199 \times$ $\mathrm{ALT})+(0.186 \times \mathrm{GGT})+(1.248 \times \mathrm{LDH})-(0.137 \times \mathrm{TBIL}$ )$-(0.194 \times$ APOA $)$. In this formula, each variable level is valued as 0 or 1 ; a value of 0 is assigned when the marker is less than or equal to the corresponding cut-off value, otherwise a value of 1 is assigned.
Assessment of performance of prognostic model and verification

The C-index is used to estimate the discrimination performance between the prognostic model and TNM staging or clinical treatment. The results are presented in Table 2. In the training cohort, the C-index for the prognostic model is 0.769 (95\% confidence interval (CI) $0.721-0.817)$, which is higher than that of TNM staging $(0.710,95 \%$ CI $0.661-0.758, \mathrm{P}=0.079)$, and clinical treatment $(0.694,95 \%$ CI 0.643-0.746, $\mathrm{P}=0.017)$. Moreover, then compare to either the TNM staging or the clinical treatment, the prognostic model shows a better discrimination capability in the validation cohort with higher C-indexes.

The prognostic accuracy of the prognostic model and TNM staging or clinical treatment in these cohorts is also assessed using tdROC analysis (Fig. 2). In the training cohort, tdROC analysis shows that the area under the ROC curves (AUCs) of the prognostic model are 0.857 for 1 -year survival, 0.845 for 3 -year survival, and 0.879 for 5 -year survival, respectively. The AUCs of TNM staging are 0.787 for 1-year survival, 0.798 for 3 -year survival, and 0.771 for 5 -year survival, respectively. The AUCs of clinical treatment are 0.771 for 1 -year survival, 0.799 for 3 -year survival, and 0.753 for 5 -year survival, respectively. Taken together, these results indicate the prognostic model have a better ability to predict survival outcomes when compare to TNM staging and clinical treatment. Similar results are observed in the validation cohort.

In addition, decision curve analysis (Fig. 3) shows that the prognostic model have a higher overall net benefit compare to traditional TNM staging and clinical treatment across the majority of the range of reasonable threshold probabilities in the training cohort and validation cohort.

\section{Construction of the prognostic model risk score based nomogram}

In this study, we built a nomogram that consist of the prognostic model risk score, TNM staging, and clinical treatment to predict 1-, 3-, and 5-year OS in the training cohort and validation cohort (Fig. 4a). Within the variables, each subtype is assigned a point. For example, locate the patient's model risk score, draw a line straight upward to the "Points" axis to determine how many points associated with that model risk score. The process is repeated for each variable, the points achieved for each covariate are summarized, and the sum on the "Total Point" axis is located. Finally, a line is drawn straight down to identify 


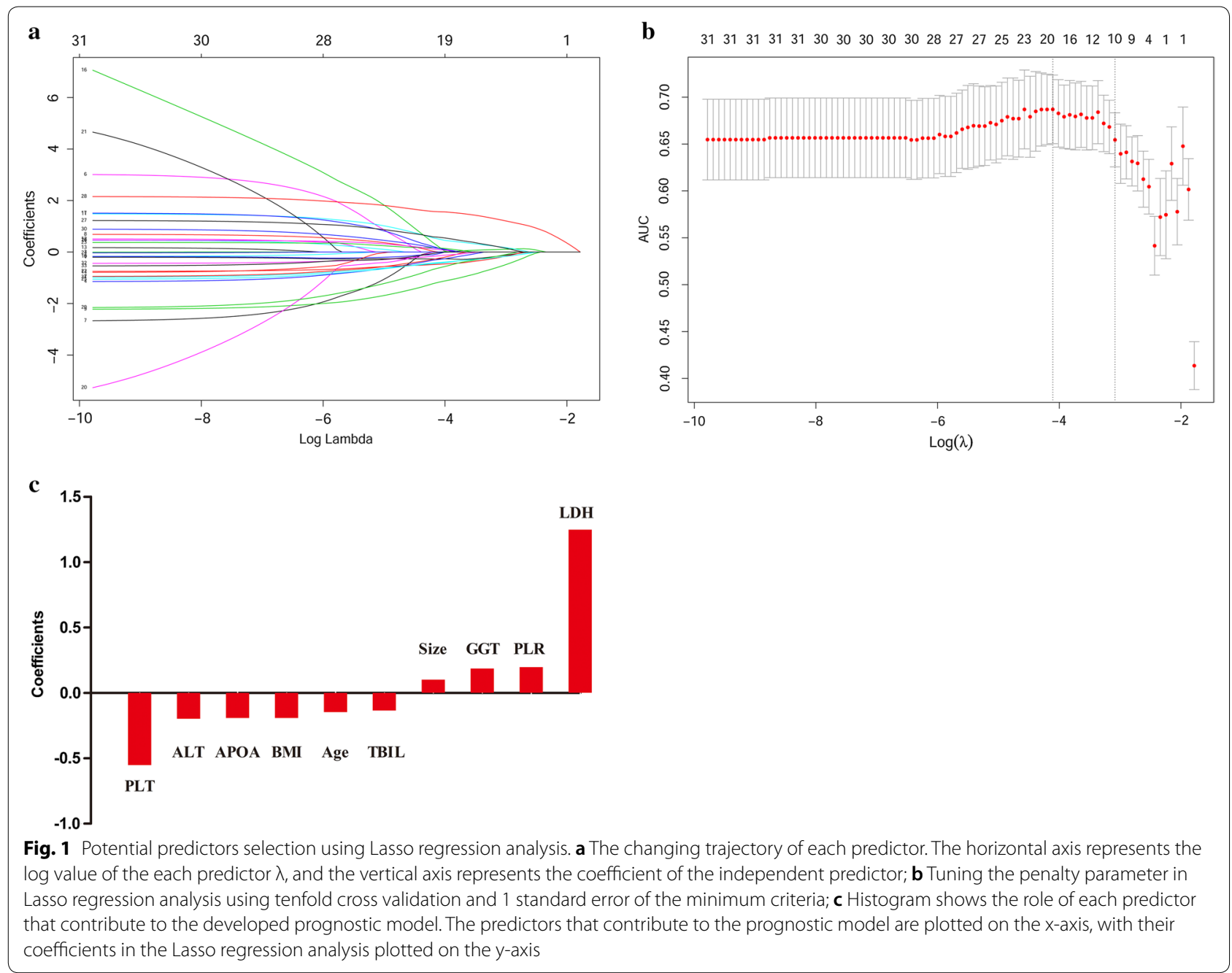

the patient's probability of OS at 1-, 3-, and 5-year. The calibration plots for the probability of survival at 1-, 3-, and 5 -year show a good match between the prediction by the nomogram and the actual observation (Fig. $4 \mathrm{~b}-\mathrm{d}$ ).

\section{Performance of the prognostic model risk score in stratifying patient risk}

The optimum cut-off value of the model risk is -0.12 (Fig. 5). Next, patients are divided into 2 subgroups (Table 3): a low-risk group (risk score $\leq-0.12$ ), and a high-risk group (risk score $>-0.12$ ). In the training cohort, for the high-risk group, the median OS of all the patients is 15 months (interquartile range (IQR): 7.0-40.0 months), the 1-, 3- and 5-year probabilities of survival are $59.3 \%, 26.7 \%$, and $11.6 \%$, respectively. For the low-risk group, the median OS is 63 months (IQR:
38.0-74.0 months), and the 1-, 3- and 5-year probabilities of survival are $98.1 \%, 76.3 \%$, and $61.0 \%$, respectively. Thelow risk group have better survival probabilities compare to the high-risk group at a 1-, 3-, and 5-year survival rate. Subsequently, Kaplan-Meier survival analysis is performed according to the stratified subgroup (Fig. 6a). Kaplan-Meier curves show that significant differences are observed in survival distributions in the stratified subgroup in the training cohort. Similar results are observed in the validation cohort.

Furthermore, stratified analyses of NSCLC HBV (+) patients with a respective stage I/II, and III/IV are performed (Fig. 6b, c). In the training cohort, the stratification by the prognostic model risk score result in significant differences in Kaplan-Meier OS curves for patients in each stage group. Furthermore, for the 
Table 2 The C-index of our model, TNM staging and Treatment for prediction of OS in the training cohort and validation cohort

\begin{tabular}{lll}
\hline Factors & C-index (95\% Cl) & $P$ \\
\hline For training cohort & & \\
Our model & $0.769(0.721-0.817)$ & \\
TNM staging & $0.710(0.661-0.758)$ & \\
Treatment & $0.694(0.643-0.746)$ & \\
Our model + TNM staging & $0.784(0.739-0.830)$ & \\
Our model vs. TNM staging & & 0.079 \\
Our model vs. treatment & & 0.017 \\
Our model vs. our model+TNM staging & & 0.218 \\
For validation cohort & & \\
Our model & $0.676(0.556-0.796)$ & \\
TNM staging & $0.654(0.552-0.755)$ & \\
Treatment & $0.647(0.517-0.777)$ & \\
Our model + TNM staging & $0.712(0.614-0.809)$ & \\
Our model vs. TNM staging & & 0.761 \\
Our model vs. treatment & & 0.754 \\
Our model vs. our model+TNM staging & & 0.205 \\
\hline
\end{tabular}

C-index concordance index, $\mathrm{Cl}$ confidence interval

$P$ values are calculated based on normal approximation using function rcorrp. cens in Hmisc package

validation cohort, this stratification also result in significant differences in OS, except for patients in stage I/II.

\section{The correlation between the prognostic model and TNM staging or clinical treatment}

Figure 7 shows the correlations between the prognostic model and TNM staging or clinical treatment in the training cohort (A) and the validation cohort (B). In this plot, the blue represents positive correlations, and the red represents negative correlations. The color intensity and the size of the circle are proportional to the correlation coefficients. In addition, the numbers in the graph show the Pearson's correlation coefficient (PCC) between different variables. The results reveal that prognostic model is positively correlated with TNM staging (PCC: training cohort: 0.48 ; validation cohort: 0.42 ) and clinical treatment (PCC: training cohort: 0.44; validation cohort: 0.29 ).

\section{Discussion}

In the present study, we first analyzed individual clinical features and serological markers based on the survival analysis approach. Then, a multi-parametric prognostic model was generated by using the Lasso regression model for predicting the OS in NSCLC HBV $(+)$ patients.
Our prognostic model showed better predictive accuracy and discriminative ability compared to traditional TNM staging and clinical treatment. The prognostic model signature successfully stratified those patients into high-risk and low-risk subgroups with significant differences in OS.

According to the results of Lasso regression analysis, the present prognostic model consisted of 10 prognostic factors: age, BMI, tumor size, PLT, PLR, ALT, GGT, LDH, TBIL, and APOA. Of the 10 prognosis-specific factors, all had been reported to be associated with OS in lung cancer patients [33-43]. These findings suggested that our results had credible prognostic value. We next compared the predictive accuracy of the prognostic model with the traditional TNM staging and clinical treatment. The data showed that the $\mathrm{C}$-index of the prognostic model was higher compared to that of TNM staging and clinical treatment in the training cohort. TdROC curve analysis showed that our prognostic model exhibited good accuracy in clinical outcome prediction either for 1-year survival (AUC $=0.857)$, 3-year survival $(\mathrm{AUC}=0.845)$, and 5-year survival $(\mathrm{AUC}=0.879$ ) of NSCLC $\mathrm{HBV}(+)$ patients in the training cohort when compared with traditional TNM staging and clinical treatment. Furthermore, the decision curve analysis showed that the prognostic model had good performance in prognosis prediction compared to TNM staging and clinical treatment in the training cohort. In the validation cohort, results were observed that were similar to the findings mentioned above.

To complement the shortcomings of current TNM staging in the prognostic assessment of NSCLC HBV $(+)$ patients, the prognostic model risk score of patients was calculated, and prediction and verification were carried out. The results showed that the prognostic model risk score successfully classified patients into high-risk and low-risk subgroups within stages I/II and III/IV, and that high-risk patients had poor survival outcomes. Therefore, even between patients in the same stage, highrisk patients needed more intensified treatment. These results implied that the prognostic model could reinforce the prognostic ability of TNM staging, and the improved prediction of individual outcomes would be useful for counselling patients, personalizing treatment, and scheduling patients' follow-up. Of note, significant positive correlations were observed among the prognostic model, TNM staging, and clinical treatment, thereby suggesting that the prognostic model could be useful in predicting the outcomes of NSCLC HBV (+), and might be useful in treatment decisions.

Compared to previous studies [44, 45], this study had the following advantages: (1) To increase prognostic 


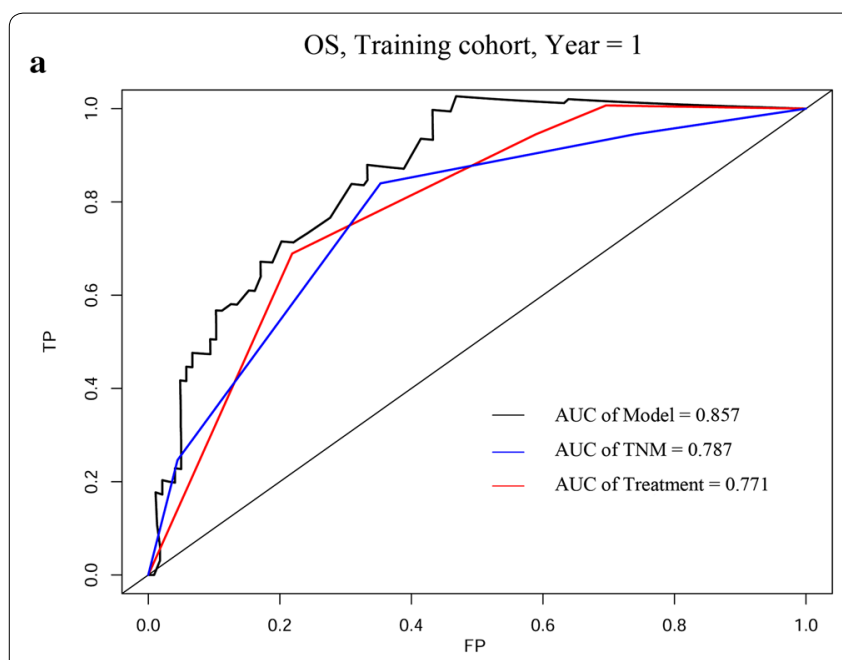

b

OS, Training cohort, Year $=3$
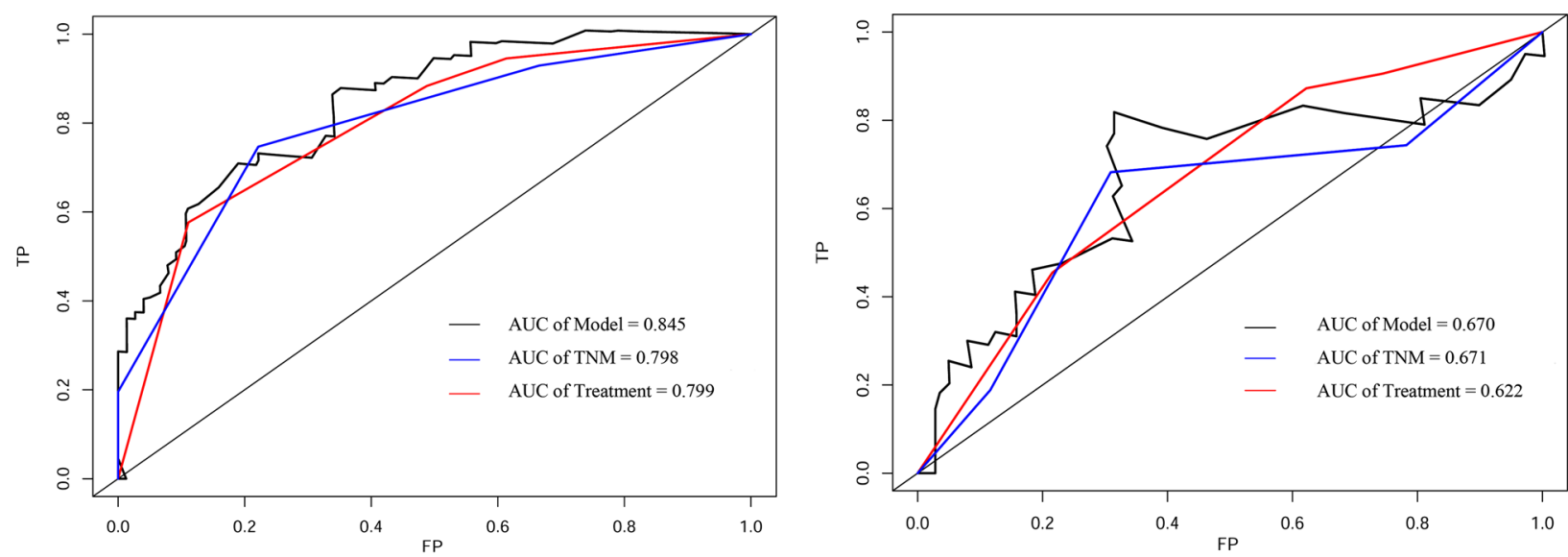

OS, Training cohort, Year $=5$
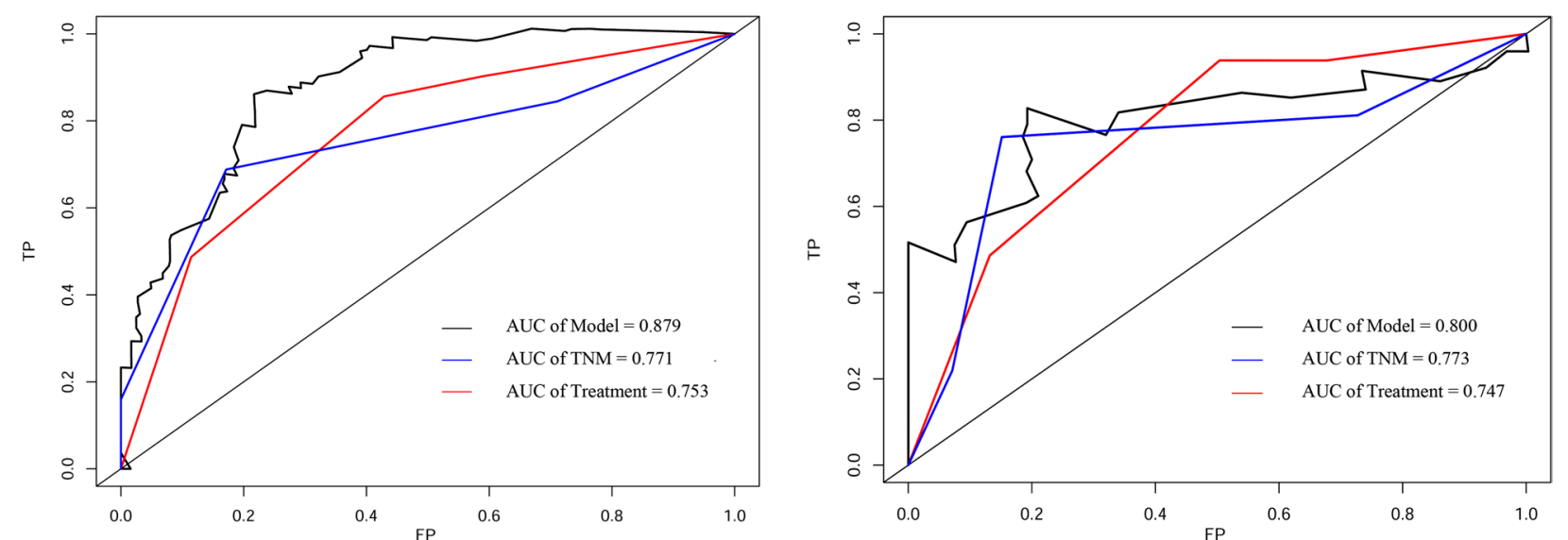

Fig. 2 Comparison of predictive accuracy between prognostic model, TNM staging, and clinical treatment using time dependent ROC curves at 1-, 3-, 5-year (a-c) in training cohort (left) and validation cohort (right) 

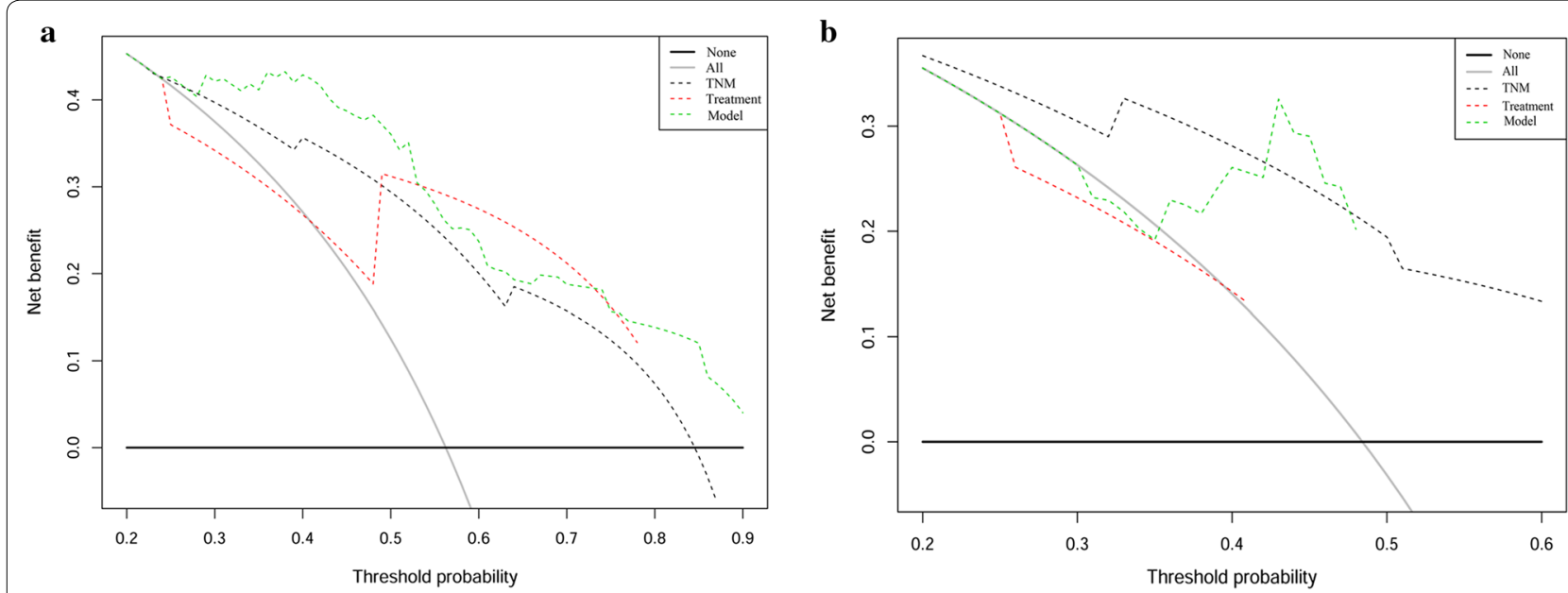

Fig. 3 Decision curve analysis for each model in training cohort (a) and validation cohort (b). The thick grey line is the net benefit for a strategy of treating all men; the thick black line is the net benefit of treating no men. The $y$-axis indicate the net benefit, which is calculated by summing the benefits (true positive results) and subtracting the harms (false positive results), weighting the latter by a factor related to the relative harm of an undetected cancer compared with the harm of unnecessary treatment

accuracy, many potential prognostic factors have been assessed. The potential prognostic factors included in this study were more than presented in previously studies. (2) We developed a prognostic model using the new algorithm Lasso regression analysis, as a statistical method for screening variables to establish a prognostic model, which enabled to adjust for model's over fitting and avoid extreme predictions. Thus, the predictive accuracy could be significantly improved, and this approach was applied in many study $[27,46,47]$. (3) The prognostic model was different from that presented in previous studies because the prognostic model did not include TNM staging. Therefore, whether it can be used for patients with TNM staging is unclear. Moreover, the C-index of the prognostic model was approximately equivalent or even higher than the previously reported model. (4) For further research, continuous variables need to be transformed into categorical variables based on the cut-off values. There were some limitations in choosing the cut-off values for continuous variables, because the cut-off values were determined by analyzed data, and different data have different cut-off values. To overcome this limitation, in this study, the continuous variables did not need to be transformed into categorical variables. Thus, this was convenient for other center applications.

However, some limitations in our study should be considered. First, this was a retrospective study, and therefore, the retrospective nature of this study cannot exclude all potential bias. Second, our endpoint was OS, and further research on the disease-free survival (DFS) should also be conducted. Third, other predictive biomarkers, such as radiomics features [48], carcinoembryonic antigen (CEA) [49], cytokeratin 19 fragment (CYFRA21-1) [49], epidermal growth factor receptor (EGFR) [50], circulating tumor cells [51], and circulating cell-free DNA [52] were not analyzed in the current study. Finally, analysis was from data obtained from a single cancer center, and the sample size was small. In the future, a large-scale, multicenter validation of the results will be required. Despite the above-mentioned shortcomings, the prognostic model was effective and may be useful in predicting the outcomes of NSCLC HBV (+) patients.

\section{Conclusions}

In conclusion, this study provided a multi-parametric prognostic model derived from clinical features and serological markers that showed favorable performance when compared to traditional TNM staging and clinical treatment for individualized OS estimation. The nomogram based on the prognostic model, TNM staging, and clinical treatment can reinforce the prognostic ability of TNM staging. Therefore, this simple, precise and understandable prognostic model may serve as a potential tool for clinicians in counselling patients, personalizing treatment, and scheduling the follow-up for NSCLC HBV (+) patients. 


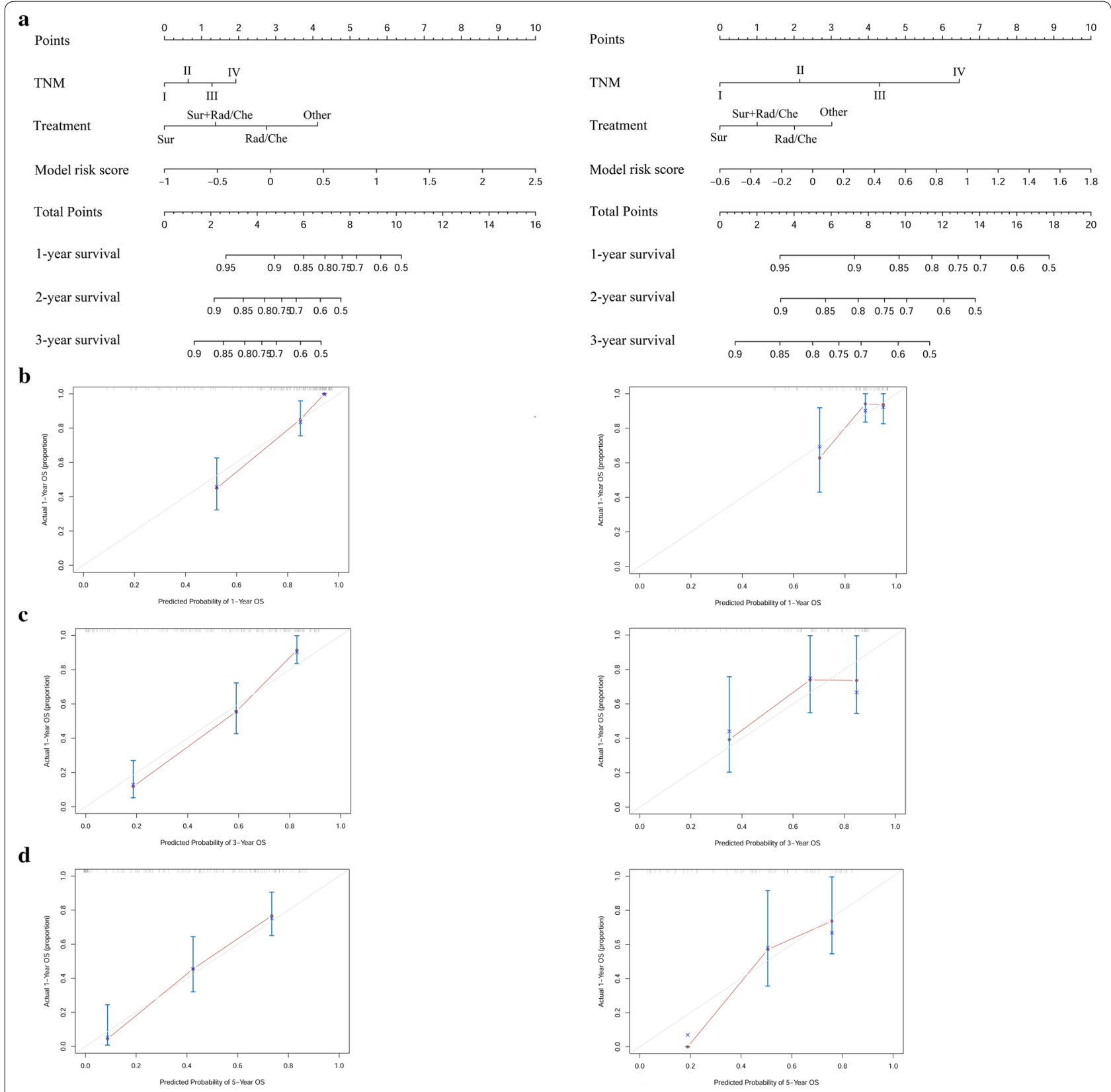

Fig. 4 The nomograms (a) are used to estimate OS for NSCLC (HBV+) patients, along with the calibration plot (b-d) for the nomograms at 1-, 3-, 5 - year in training cohort (left) and validation cohort (right) 


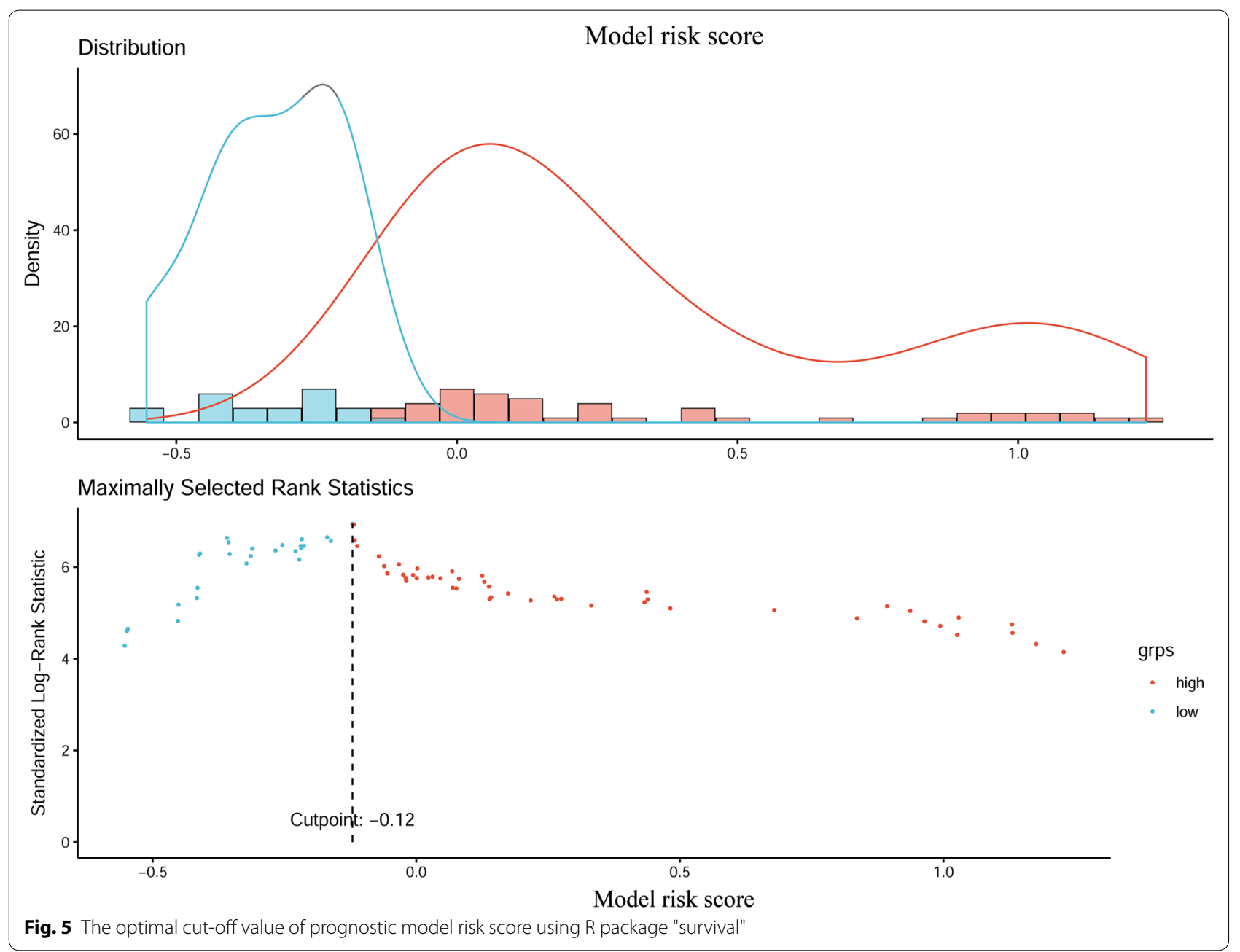

Table 3 OS and OS rate in high-risk and low-risk groups according to our model risk score in the training and validation cohort

\begin{tabular}{|c|c|c|c|c|c|c|}
\hline \multirow[t]{2}{*}{ Parameter } & \multicolumn{3}{|l|}{ Training cohort } & \multicolumn{3}{|l|}{ Validation cohort } \\
\hline & High-risk group & Low-risk group & Total & High-risk group & Low-risk group & Total \\
\hline No. of patients & 86 & 59 & 145 & 28 & 28 & 56 \\
\hline \multicolumn{7}{|l|}{ OS } \\
\hline Median & 15.0 & 63.0 & & 12.5 & 59.0 & \\
\hline IQR & $7.0-40.0$ & $38.0-74.0$ & & $7.25-21.50$ & $33.50-72.25$ & \\
\hline \multicolumn{7}{|l|}{ No. of OS } \\
\hline At 1 year & $51(59.3 \%)$ & $58(98.1 \%)$ & 109 (69.7\%) & $16(57.1 \%)$ & $25(89.3 \%)$ & $41(73.2 \%)$ \\
\hline At 3 year & $23(26.7 \%)$ & $45(76.3 \%)$ & $68(46.9 \%)$ & $4(14.3 \%)$ & $20(71.4 \%)$ & $24(42.9 \%)$ \\
\hline At 5 year & $10(11.6 \%)$ & $36(61.0 \%)$ & $46(31.7 \%)$ & $1(3.6 \%)$ & $14(50.0 \%)$ & $15(26.8 \%)$ \\
\hline
\end{tabular}

OS overall survival, IQR interquartile range 

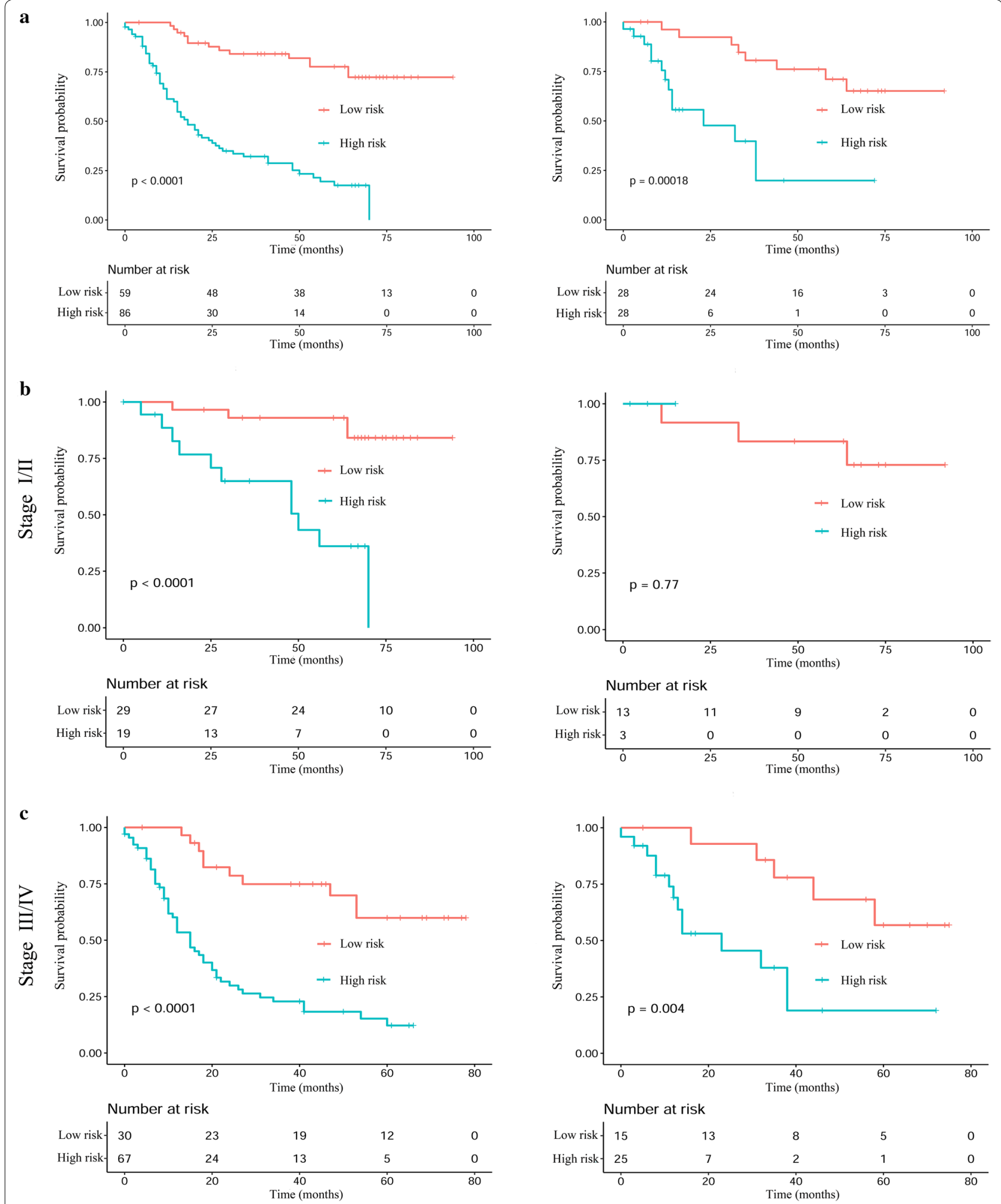

Fig. 6 Kaplan-Meier analyses of OS according to the prognostic model risk score classifier in subgroups of NSCLC (HBV+) patients in the training cohort (left) and the validation cohort (right): (a) total patients; (b) stage I/II; (c) stage III/IV 

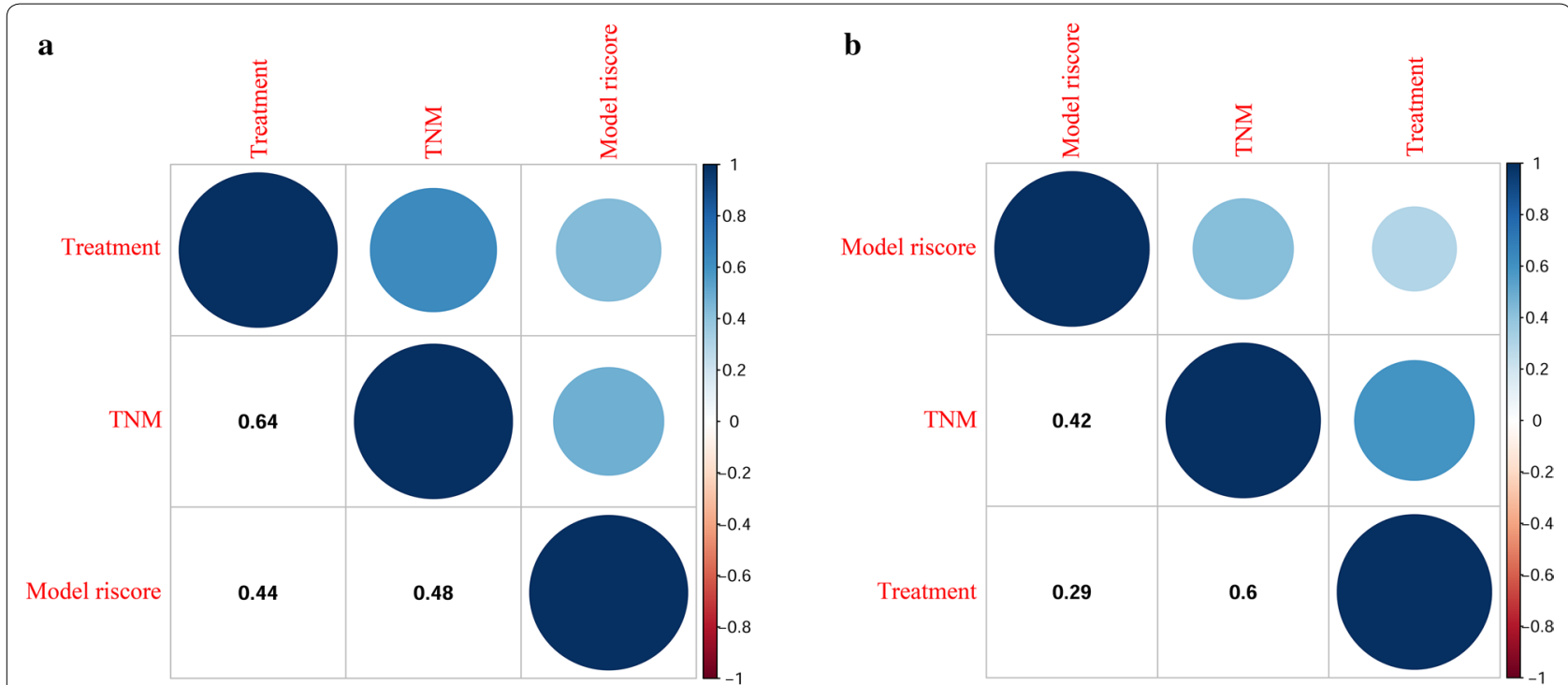

Fig. 7 The correlations between the prognostic model and TNM staging or clinical treatment in training cohort (a) and validation cohort (b)

\section{Abbreviations}

AUC: The areas under ROC curve; BMI: Body mass index; TNM: Tumor node metastasis stage; Sur: Surgery; Rad: Radiotherapy; Che: Chemotherapy; WBC White blood cell; NLR: Neutrophil/lymphocyte ratio; PLR: Platelet/lymphocyte ratio; ALB: Albumin; ALT: Alanine transaminase; AST: Aspartate aminotransferase; SLR: AST/ALT ratio; ALP: Alkaline phosphatase; APOA: Apolipoprotein Al; APOB: Apolipoprotein B; ABR: APOA/APOB ratio; CRP: C-reactive protein; CAR : C-reactive protein/albumin ratio; LDH: Lactic dehydrogenase; GGT: Glutamyl transpeptidase; TBIL: Total bilirubin; DBIL: Direct bilirubin; PNI: Prognostic nutritional index; PI: Prognostic index; PCC: Pearson's correlation coefficient; GPS: Glasgow prognostic score; IQR: Interquartile range.

\section{Acknowledgements}

We thank Sun Yat-sen University Cancer Center for providing support on research conditions in this study.

\section{Authors' contributions}

All authors contributed to this manuscript, including conception and design $(H C, Y W X, X H)$, acquisition of data (SLC, YJL, SGP), analysis and interpretation of data $(\mathrm{HQH}, \mathrm{CCL}, \mathrm{LZ})$, material support (SLC), study supervision (HC, YWX, XH). All authors read and approved the final manuscript.

\section{Funding}

This work was supported by the National Natural Science Foundation of China (No. 31600632) and funded by the Natural Science Foundation of Guangdong Province (2018A030307079).

\section{Availability of data and materials}

The datasets analyzed during the current study are not publicly available due to patient privacy concerns, but are available from the corresponding author on reasonable request.

\section{Ethics approval and consent to participate}

This study was approved by the Clinical Research Ethics Committee of the Sun Yat-sen University Cancer Center, and all patients provided written informed consent at the first visit to our center.

\section{Consent for publication}

Not applicable.

\section{Competing interests}

The authors declare that they have no competing interests.

\section{Author details}

${ }^{1}$ State Key Laboratory of Oncology in South China, Collaborative Innovation Center for Cancer Medicine, Guangdong Key Laboratory of Nasopharyngeal Carcinoma Diagnosis and Therapy, Sun Yat-Sen University Cancer Center, 651 Dongfeng Road East, Guangzhou 510060, People's Republic of China. 2 Department of Thoracic Surgery, Maoming People's Hospital, Maoming 525000, Guangdong, People's Republic of China. ${ }^{3}$ Department of Clinical Laboratory, Maoming People's Hospital, Maoming 525000, Guangdong, People's Republic of China. ${ }^{4}$ Department of Pathology Laboratory, Maoming People's Hospital, Maoming 525000, Guangdong, People's Republic of China. ${ }^{5}$ Department of Clinical Laboratory, The Cancer Hospital of Shantou University Medical College, Precision Medicine Research Center, Shantou University Medical College, Shantou 515041, People's Republic of China.

Received: 20 August 2020 Accepted: 29 October 2020

Published online: 19 November 2020

\section{References}

1. Siegel RL, Miller KD, Jemal A. Cancer statistics, 2016. CA Cancer J Clin. 2016;66(1):7-30.

2. Le Pechoux C. Role of postoperative radiotherapy in resected nonsmall cell lung cancer: a reassessment based on new data. Oncologist. 2011;16(5):672-81.

3. Aggarwal A, Lewison G, Idir S, Peters M, Aldige C, Boerckel W, Boyle P, Trimble EL, Roe P, Sethi T, et al. The state of lung cancer research: a global analysis. J Thorac Oncol. 2016;11(7):1040-50.

4. Cui Y, Jia J. Update on epidemiology of hepatitis B and C in China. J Gastroenterol Hepatol. 2013;28(Suppl 1):7-10.

5. Song C, Lv J, Liu Y, Chen JG, Ge Z, Zhu J, Dai J, Du LB, Yu C, Guo Y, et al. Associations between hepatitis $B$ virus infection and risk of all cancer types. JAMA Netw Open. 2019;2(6):e195718.

6. Engels EA, Cho ER, Jee $\mathrm{SH}$. Hepatitis B virus infection and risk of nonHodgkin lymphoma in South Korea: a cohort study. Lancet Oncol. 2010;11(9):827-34.

7. Liu X, Li X, Jiang N, Lei Y, Tang LL, Chen L, Zhou GQ, Sun Y, Yue D, Guo R, et al. Prognostic value of chronic hepatitis $B$ virus infection in patients with nasopharyngeal carcinoma: analysis of 1301 patients from an endemic area in China. Cancer. 2014;120(1):68-76. 
8. Wang F, Xu RH, Luo HY, Zhang DS, Jiang WQ, Huang HQ, Sun XF, Xia ZJ, Guan ZZ. Clinical and prognostic analysis of hepatitis B virus infection in diffuse large B-cell lymphoma. BMC Cancer. 2008;8:115.

9. Teng CJ, Liu HT, Liu CY, Hsih CH, Pai JT, Gau JP, Liu JH, Chiou TJ, Hsu $\mathrm{HC}$, Chen PM, et al. Chronic hepatitis virus infection in patients with multiple myeloma: clinical characteristics and outcomes. Clinics. 2011;66(12):2055-61.

10. Greene FL, Sobin LH. The TNM system: our language for cancer care. J Surg Oncol. 2002;80(3):119-20.

11. Cagle PT. Lung carcinoma staging problems. Surg Pathol Clin. 2010:3(1):61-9.

12. Vielh P, Spano JP, Grenier J, Le Chevalier T, Soria JC. Molecular prognostic factors in resectable non-small cell lung cancer. Crit Rev Oncol Hematol. 2005;53(3):193-7.

13. Burke HB. Outcome prediction and the future of the TNM staging system. J Natl Cancer Inst. 2004;96(19):1408-9.

14. Thakur MK, Gadgeel SM. Predictive and prognostic biomarkers in nonsmall cell lung cancer. Semin Respir Crit Care Med. 2016;37(5):760-70.

15. Bianconi F, Fravolini ML, Bello-Cerezo R, Minestrini M, Scialpi M, Palumbo B. Evaluation of shape and textural features from CT as prognostic biomarkers in non-small cell lung cancer. Anticancer Res. 2018:38(4):2155-60

16. Matikas A, Syrigos KN, Agelaki S. Circulating biomarkers in non-smallcell lung cancer: current status and future challenges. Clin Lung Cancer. 2016;17(6):507-16.

17. Edge SB, Compton CC. The American Joint Committee on Cancer: the 7th edition of the AJCC cancer staging manual and the future of TNM. Ann Surg Oncol. 2010;17(6):1471-4.

18. Diem S, Schmid S, Krapf M, Flatz L, Born D, Jochum W, Templeton AJ, Fruh M. Neutrophil-to-Lymphocyte ratio (NLR) and Platelet-toLymphocyte ratio (PLR) as prognostic markers in patients with nonsmall cell lung cancer (NSCLC) treated with nivolumab. Lung Cancer. 2017:111:176-81.

19. Lee H, Choi YH, Sung HH, Han DH, Jeon HG, Chang Jeong B, Seo SI, Jeon SS, Lee HM, Choi HY. De ritis ratio (AST/ALT) as a significant prognostic factor in patients with upper tract urothelial cancer treated with surgery. Clin Genitourin Cancer. 2017:15(3):e379-85.

20. Chang SJ, Hou MF, Tsai SM, Wu SH, Hou LA, Ma H, Shann TY, Tsai LY. The association between lipid profiles and breast cancer among Taiwanese women. Clin Chem Lab Med. 2007:45(9):1219-23.

21. Deng TB, Zhang J, Zhou YZ, Li WM. The prognostic value of C-reactive protein to albumin ratio in patients with lung cancer. Medicine. 2018;97(50):e13505.

22. Kasymjanova G, MacDonald N, Agulnik JS, Cohen V, Pepe C, Kreisman $H$, Sharma R, Small D. The predictive value of pre-treatment inflammatory markers in advanced non-small-cell lung cancer. Curr Oncol. 2010;17(4):52-8

23. He X, Li JP, Liu XH, Zhang JP, Zeng QY, Chen H, Chen SL. Prognostic value of C-reactive protein/albumin ratio in predicting overall survival of Chinese cervical cancer patients overall survival: comparison among various inflammation based factors. J Cancer. 2018:9(10):1877-84.

24. Shiba H, Horiuchi T, Sakamoto T, Furukawa K, Shirai Y, lida T, Fujiwara Y, Haruki K, Yanaga K. Glasgow prognostic score predicts therapeutic outcome after hepatic resection for hepatocellular carcinoma. Oncol Lett. 2017;14(1):293-8.

25. Diboun I, Wernisch L, Orengo CA, Koltzenburg M. Microarray analysis after RNA amplification can detect pronounced differences in gene expression using limma. BMC Genomics. 2006;7:252.

26. Goeman JJ. L1 penalized estimation in the Cox proportional hazards model. Biometrical J. 2010:52(1):70-84.

27. Tibshirani R. The lasso method for variable selection in the Cox model. Stat Med. 1997;16(4):385-95.

28. Vickers AJ, Cronin AM, Elkin EB, Gonen M. Extensions to decision curve analysis, a novel method for evaluating diagnostic tests, prediction models and molecular markers. BMC Med Inform Decis Mak. 2008;8:53.

29. Heagerty PJ, Lumley T, Pepe MS. Time-dependent ROC curves for censored survival data and a diagnostic marker. Biometrics. 2000;56(2):337-44.

30. Schroder MS, Culhane AC, Quackenbush J, Haibe-Kains B. survcomp: an R/Bioconductor package for performance assessment and comparison of survival models. Bioinformatics. 2011;27(22):3206-8.
31. Shim JH, Jun MJ, Han S, Lee YJ, Lee SG, Kim KM, Lim YS, Lee HC. Prognostic nomograms for prediction of recurrence and survival after curative liver resection for hepatocellular carcinoma. Ann Surg. 2015;261 (5):939-46.

32. Williams S. Pearson's correlation coefficient. N Z Med J. 1996;109(1015):38.

33. Jin S, Cao S, Xu S, Wang C, Meng Q, Yu Y. Clinical impact of pretreatment prognostic nutritional index (PNI) in small cell lung cancer patients treated with platinum-based chemotherapy. Clin Respir J. 2018;12(9):2433-40.

34. Nakagawa T, Toyazaki T, Chiba N, Ueda Y, Gotoh M. Prognostic value of body mass index and change in body weight in postoperative outcomes of lung cancer surgery. Interact Cardiovasc Thorac Surg. 2016;23(4):560-6.

35. Xu S, Xi J, Jiang W, Lu S, Wang Q. Solid component and tumor size correlate with prognosis of stage IB lung adenocarcinoma. Ann Thorac Surg. 2015;99(3):961-7.

36. Wang YQ, Zhi QJ, Wang XY, Yue DS, Li K, Jiang RC. Prognostic value of combined platelet, fibrinogen, neutrophil to lymphocyte ratio and platelet to lymphocyte ratio in patients with lung adenosquamous cancer. Oncol Lett. 2017;14(4):4331-8.

37. Kim SH, Lee HW, Go SI, Lee SI, Lee GW. Clinical significance of the preoperative platelet count and platelet-to-lymphocyte ratio (PLT-PLR) in patients with surgically resected non-small cell lung cancer. Oncotarget. 2016;7(24):36198-206.

38. Pilling JE, Dusmet ME, Ladas G, Goldstraw P. Prognostic factors for survival after surgical palliation of malignant pleural effusion. J Thorac Oncol. 2010;5(10):1544-50

39. Shi H, Huang H, Pu J, Shi D, Ning Y, Dong Y, Han Y, Zarogoulidis P, Bai C. Decreased pretherapy serum apolipoprotein $A-1$ is associated with extent of metastasis and poor prognosis of non-small-cell lung cancer. Onco Targets Ther. 2018;11:6995-7003.

40. Kim JH, Seo SW, Chung CH. What factors are associated with early mortality in patients undergoing femur surgery for metastatic lung cancer? Clin Orthop Relat Res. 2018;476(9):1815-22.

41. Bozkaya Y, Yazici O. Prognostic significance of gamma-glutamyl transferase in patients with metastatic non-small cell lung cancer. Expert Rev Mol Diagn. 2019;19(3):267-72.

42. Mezquita L, Auclin E, Ferrara R, Charrier M, Remon J, Planchard D, Ponce $S$, Ares LP, Leroy L, Audigier-Valette C, et al. Association of the lung immune prognostic index with immune checkpoint inhibitor outcomes in patients with advanced non-small cell lung cancer. JAMA Oncol. 2018:4(3):351-7.

43. Li N, Xu M, Cai MY, Zhou F, Li CF, Wang BX, Ou W, Wang SY. Elevated serum bilirubin levels are associated with improved survival in patients with curatively resected non-small-cell lung cancer. Cancer Epidemiol. 2015;39(5):763-8.

44. Chen S, Lai Y, He Z, Li J, He X, Shen R, Ding Q, Chen H, Peng S, Liu W. Establishment and validation of a predictive nomogram model for nonsmall cell lung cancer patients with chronic hepatitis B viral infection. J Transl Med. 2018;16(1):116.

45. Chen S, Li X, Lv H, Wen X, Ding Q, Xue N, Su H, Chen H. Prognostic dynamic nomogram integrated with inflammation-based factors for nonsmall cell lung cancer patients with chronic hepatitis B viral infection. Int J Biol Sci. 2018;14(13):1813-21.

46. Moons KG, Donders AR, Steyerberg EW, Harrell FE. Penalized maximum likelihood estimation to directly adjust diagnostic and prognostic prediction models for overoptimism: a clinical example. J Clin Epidemiol. 2004;57(12):1262-70.

47. Srivastava S, Chen L. Comparison between the stochastic search variable selection and the least absolute shrinkage and selection operator for genome-wide association studies of rheumatoid arthritis. BMC Proc. 2009;3(Suppl 7):S21.

48. Huang Y, Liu Z, He L, Chen X, Pan D, Ma Z, Liang C, Tian J, Liang C. Radiomics signature: a potential biomarker for the prediction of disease-free survival in early-stage (I or II) non-small cell lung cancer. Radiology. 2016;281(3):947-57.

49. Baek AR, Seo HJ, Lee JH, Park SW, Jang AS, Paik SH, Koh ES, Shin HK, Kim DJ. Prognostic value of baseline carcinoembryonic antigen and cytokeratin 19 fragment levels in advanced non-small cell lung cancer. Cancer Biomark. 2018;22(1):55-62.

50. Romero-Ventosa EY, Blanco-Prieto S, Gonzalez-Pineiro AL, RodriguezBerrocal FJ, Pineiro-Corrales G. Paez de la Cadena M: Pretreatment levels of the serum biomarkers CEA, CYFRA 21-1, SCC and the soluble EGFR 
and its ligands EGF, TGF-alpha, HB-EGF in the prediction of outcome in erlotinib treated non-small-cell lung cancer patients. Springerplus. 2015;4:171.

51. Coco S, Alama A, Vanni I, Fontana V, Genova C, Dal Bello MG, Truini A, Rijavec E, Biello F, Sini C, et al. Circulating cell-free DNA and circulating tumor cells as prognostic and predictive biomarkers in advanced nonsmall cell lung cancer patients treated with first-line chemotherapy. Int J Mol Sci. 2017;18(5):1035.
52. Zhang Y, Zheng H, Zhan Y, Long M, Liu S, Lu J, Zang H, Fan S. Detection and application of circulating tumor cell and circulating tumor DNA in the non-small cell lung cancer. Am J Cancer Res. 2018;8(12):2377-86.

\section{Publisher's Note}

Springer Nature remains neutral with regard to jurisdictional claims in published maps and institutional affiliations.
Ready to submit your research? Choose BMC and benefit from:

- fast, convenient online submission

- thorough peer review by experienced researchers in your field

- rapid publication on acceptance

- support for research data, including large and complex data types

- gold Open Access which fosters wider collaboration and increased citations

- maximum visibility for your research: over $100 \mathrm{M}$ website views per year

At BMC, research is always in progress.

Learn more biomedcentral.com/submissions 